\title{
Marriage of Individual Pharmacists' Achievement on Key Performance Indicators and Teaching Responsibilities
}

\author{
Lalitha Raman-Wilms
}

$\mathrm{E}_{\mathrm{s}}^{\mathrm{n}}$ ntry-to-practice Doctor of Pharmacy (PharmD) curricula focus on advanced clinical knowledge and skills, enabling graduates to be competent and confident in providing direct patient care in various practice settings. A significant component of the 4-year program is experiential education, involving both early and advanced pharmacy practice experiences. ${ }^{1}$ These programs will require that many more rotations be offered, with greater breadth, quantity, and sophistication of experiences. To create an effective training environment for students and to accommodate the larger number of rotations, some educational programs have indicated that they would like students to be able to "add value" to the practice sites by contributing to patient care. This contribution would offset the increased demand on pharmacist preceptors associated with providing enhanced experiences to a larger number of students. To contribute effectively to patient care to any relevant degree, students will need to assume direct patient care responsibilities.

Educational institutions, practice sites, and professional associations have proposed various strategies to facilitate this enhanced training. Models for pharmacy residencies and student training have indicated the importance of both residents and students undertaking patient care activities that are known to improve patient outcomes. ${ }^{2}$ The University of North Carolina has suggested a "layered learning practice model" (LLPM) whereby each student and resident trainee acts as a "pharmacist extender", providing care under the guidance of an attending pharmacist who takes overall responsibility. ${ }^{3}$

In this issue of the CJHP, Gorman and Slavik ${ }^{4}$ and Fernandes and others ${ }^{5}$ debate the importance of clinical pharmacy key performance indicators (cpKPIs) as a component of assessing the performance of individual pharmacists. A cpKPI is an activity that reflects a desired practice linked to direct patient care and that is "associated with evidence of impact on meaningful patient outcomes". 5

Fernandes and others ${ }^{6}$ used a pan-Canadian consensusbuilding process to identify $8 \mathrm{cpKPIs}$, specifically medication reconciliation on both admission and discharge; interprofessional patient care rounds; number of patients with completed pharmaceutical care plans; number of drug therapy problems resolved; percentage of patients receiving proactive, comprehensive care by a pharmacist within a team environment; and patient

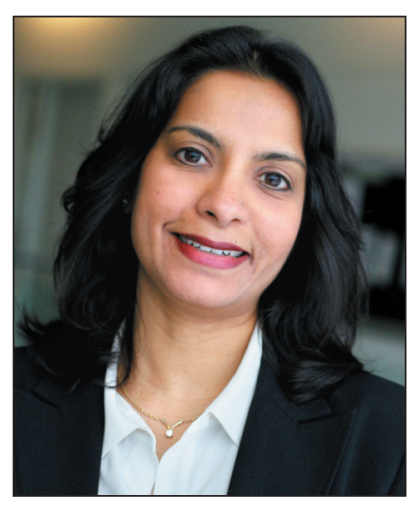
education, both during the hospital stay and at discharge.

Performance indicators have been used as tools for various types of work and in various settings. They represent targets to assist in achieving and maintaining an expected level of practice; in the medical setting, they provide quantitative measures of quality care. Pharmacy-related performance indicators serve as benchmarks that enable pharmacists to "refocus and prioritize their patient care efforts" on activities known to benefit and influence important outcomes. ${ }^{5}$ When widely applied, they can promote professional accountability and responsibility for clinical care. However, when only limited resources are available, many institutions and pharmacists will find it challenging to expand existing services or incorporate new services to meet established cpKPIs, while also expanding educational experiences for students.

If there is agreement (nationally, provincially, or locally) about the benefit of cpKPIs, how can we assist institutions and individual hospital pharmacists to embrace the use of these indicators, while also helping them to expand their teaching of future practitioners? Can innovative partnerships between educational institutions and practising pharmacists be created, whereby students undertaking advanced pharmacy practice rotations will have a defined minimum level of knowledge and skills necessary for patient care, enabling them to contribute to positive patient outcomes and thereby assist pharmacists in 
complying with cpKPI requirements? Can such partnerships, combined with relevant supports from educational institutions to preceptors and sites, enable hospital pharmacists to enhance their compliance with performance indicators, while ensuring that students are receiving a quality educational experience?

At the University of North Carolina Hospitals, the LLPM model has allowed for both an increase in educational opportunities for student learners and a significant increase in the number of medication-related services provided by the pharmacy, which has in turn enhanced overall patient care. ${ }^{7}$ Examples of the services improved through student participation are obtaining medication histories and discharge counselling. In one study unit, the latter skyrocketed from $0 \%$ to $78 \%$ ! In areas where such services were already in place, the institution significantly increased the number of patients receiving the services. For example, one study unit increased the rate of medication reconciliation on admission from $45 \%$ to $100 \%$ when students were included as part of the team. Similarly, there was a significant increase in drug therapy adjustments at admission, from $22 \%$ to $40 \%$.

For models such as LLPM to work well, with students assuming responsibilities for patient care, the educational institution and the hospital training site will have to agree upon the key concepts and skills that students must have before the rotation begins. Also, including students on longitudinal rotations can be beneficial to the site and the students, as their comfort level will increase and learning can be enhanced.

With the development of Canadian cpKPIs and the implementation of new PharmD programs, it is time for educational institutions and hospital pharmacy departments to continue their national discussion about what a Canadian training model would look like and what expectations are reasonable for students undertaking advanced pharmacy practice rotations. This discussion began when national associations came together in 2012 to discuss the future of pharmacy experiential education in Canada. ${ }^{8}$ Much of the discussion to date has focused on experiential models to increase capacity and supports required for preceptors. One of the national action priorities identified at the 2012 workshop was "identification and promotion of how students add value to host organizations". Given that some PharmD programs will soon start administering advanced experiential rotations, it is urgent that we continue discussions of how best to enable students to add value to sites and thereby enhance patient care, to enable pharmacists to meet cpKPIs, and to move the profession forward, and that we elevate existing local discussions to the national level.

References

1. Accreditation standards for the first professional degree in pharmacy programs: effective January 2013. Toronto (ON): Canadian Council for Accreditation of Pharmacy Programs; 2012 [cited 2014 Jan 15]. Available from: www. ccapp-accredit.ca/site/pdfs/university/CCAPP_accred_standards_degree_ 2012.pdf

2. Ashby DM. Permission granted [Harvey A K Whitney lecture]. Am J Health Syst Pharm. 2011;68(16):1497-504. Erratum: Am J Health Syst Pharm. 2011;68(19):1769.

3. Pinelli NR. The layered learning practice model: toward a consistent model of pharmacy practice [abstract]. Bethesda (MD): ASHP Research and Education Foundation; [cited 214 Jan 15]. Available from: www.ashpfoundation.org/ PinelliAbstract

4. Gorman S, Slavik R. Should key performance indicators be a component of performance assessment for individual clinical pharmacists? The "pro" side. Can J Hosp Pharm. 2014;67(2):165-6.

5. Fernandes OA, Le Piane F, Ahmed H, Toombs K. Should key performance indicators be a component of performance assessment for individual clinical pharmacists? The "con" side. Can J Hosp Pharm. 2014;67(2):166-8.

6. Fernandes O, Gorman S, Slavik R, Semchuk W, Doucette D, Bannerman H, et al. What are the appropriate clinical pharmacy key performance indicators for hospital pharmacists? [abstract]. Pharmacotherapy. 2013;33(10):e208.

7. Daniels R. Overcoming challenges to implementation-how to surmount the most significant hurdles? [presentation]. Annual meeting of American College of Clinical Pharmacy; 2012 Oct 20-24; Hollywood (FL).

8. Whetstone Consulting Inc. The future of pharmacy experiential education in Canada: a stakeholder workshop. Final report for review and consultation. Association of Faculties of Pharmacy of Canada; 2012 Nov 16 [revised 2013 Jan 22; cited 2014 Jan 15]. Available from: www.afpc.info/content/finalreport-future-pharmacy-experiential-education-canada-stakeholder-workshop

Lalitha Raman-Wilms, BScPhm, PharmD, FCSHP, is Associate Professor and Associate Dean, Professional Programs with the Leslie Dan Faculty of Pharmacy, University of Toronto, Toronto, Ontario. She is also an Associate Editor with the CJHP.

Competing interests: Dr Raman-Wilms has oversight for administering experiential education rotations for students in the Leslie Dan Faculty of Pharmacy, University of Toronto.

\section{Address correspondence to:}

Dr Lalitha Raman-Wilms

Leslie Dan Faculty of Pharmacy

University of Toronto

144 College Street

Toronto ON M5S 3M2

e-mail: I.raman.wilms.a@utoronto.ca 